\title{
Self-Care and Family Support among People with Type 2 Diabetes
}

\author{
Shashi Kandel, M.B.B.S. ${ }^{1}$, Wit Wichaidit, Ph.D. ${ }^{2}$ \\ 'Department of Health Services, Ministry of Health and Population, Government of Nepal, Kathmandu, Nepal. \\ ${ }^{2}$ Epidemiology Unit, Faculty of Medicine, Prince of Songkla University, Hat Yai, Songkhla 90110, Thailand. \\ Received 26 March 2020 • Revised 12 May 2020 • Accepted 16 May 2020 • Published online 10 August 2020
}

\section{Abstract:}

Objective: To assess the prevalence of self-care practices, and family support among people with type 2 diabetes.

Material and Methods: We conducted a cross-sectional study among outpatients for people with type 2 diabetes, at a teaching hospital in Kathmandu, Nepal. We modified the Summary of Diabetes Self-Care Activities, and Diabetes Family Behavior Checklist scales; to measure self-care practices and perceived family support, respectively, so as to better suit the Nepali context. We performed an exploratory factor analysis to identify independent, latent dimensions of family support.

Results: We recruited 411 patients (56.9\% females), aged between 25 and 92 . From these, we found high levels of adherence to daily intakes of the oral hypoglycemic agent (98.2\%) and insulin (100.0\%), daily physical activity (86.4\%) and daily vegetable consumption (78.3\%). Respondents commonly reported that they, and their family members ate meals together $(98.1 \%)$. Family members also suggested things to help them take their medications on time (89.5\%) and additionally helped them to decide on changes based on their glucose test results (84.2\%). Exploratory factor analysis uncovered three behavior dimensions: nagging and arguing (“authoritarian”), praise and encouragement (“supportive") and plan-making (“planning”).

Conclusion: We presented data on self-care as well as family support among people with type 2 diabetes, tailored to the local context. From the data a high level of medication adherence and daily physical activity was observed. "Eating together" was the most reported family support behavior. We identified three dimensions of family support behaviors, which are potentially helpful for future health promotion programs, and provides a methodological basis for future studies in other low and middle-income countries.

Keywords: family support, self-care practices, type 2 diabetes

Contact: Shashi Kandel, M.B.B.S.

Department of Health Services, Ministry of Health and Population,

Government of Nepal, Kathmandu, Nepal.

E-mail: 6110320019@psu.ac.th
J Health Sci Med Res 2021;39(1):23-33 doi: $10.31584 /$ jhsmr.2020756 www.jhsmr.org

( 2020 JHSMR. Hosting by Prince of Songkla University. All rights reserved.

This is an open access article under the CC BY-NC-ND license

(http://www.jhsmr.org/index.php/jhsmr/about/editorialPolicies\#openAccessPolicy). 


\section{Introduction}

In 2017, there were 425 million adults, aged 20 to 70 , who were suffering from diabetes globally; $90.0 \%$ of whom had type 2 diabetes mellitus (DM). ${ }^{1}$ Control of blood glucose levels, also known as glycemic control, helps to prevent or delay DM-related microvascular and macrovascular complications. ${ }^{2}$ Self-care practices that contribute to achieving glycemic control and reducing complications in people with type 2 diabetes include medication adherence, dietary behaviors, physical activity, self-monitoring of blood glucose levels and foot care. ${ }^{3-5}$ However, adherence to self-care practices may vary by activity $^{6}$, and self-care practices in each country vary in forms along with prevalence; based on each country's context.

Family support is the support provided by any family member to a person having a disability, which may include a child, an adult, or a parent. Many studies have shown that family support can improve self-care among diabetic patients. ${ }^{7-9}$ However, the expression and function of family support may vary according to culture. ${ }^{10-12}$ Culturally, nuanced care, strategies, and meaningful approaches are to be considered for better self-care management among people with type 2 diabetes. However, previous studies on family support have been conducted in high-income countries ${ }^{7-9}$, and the findings may not be generalizable to low- and middle-income countries.

Little information is available about diabetes selfcare practices and family support among people with type 2 diabetes in Nepal; a low-income country in South Asia, undergoing an epidemiological transition. Such information can contribute to improvement in diabetes health promotion program designs and planning. This study; therefore, aimed to assess the prevalence of self-care practices and family support among people with type 2 diabetes in Nepal.

\section{Material and Methods}

We conducted a hospital-based, cross-sectional study in Kathmandu, Nepal; from October to December, 2019, at Tribhuvan University Teaching Hospital's (TUTH) outpatient department, among people with type 2 diabetes. The TUTH's endocrinology outpatient department runs three days per week, and the general practice outpatient provides service six days per week. Both outpatient department receives, manage, and follow-up the people with type 2 diabetes.

We calculated the sample size based on an estimate of the proportion of participants having a high level of diabetes self-care behaviors. No previous estimate for this proportion could be found in the literature, so we assumed that $50.0 \%$ of people with type 2 diabetes had high adherence to self-care behaviors. Using a $95.0 \%$ level of confidence and a $5.0 \%$ margin of error, a sample size of 385 was deemed sufficient. We added a $10.0 \%$ non-response rate to the calculated sample size; hence, the final sample size was increased to 428 individuals.

After contacting the hospital administrator and explaining the objectives of the study, permission was given, and letters were sent to the heads of the Departments of Endocrinology and General Practice. Verbal permission to conduct the study along with access to the medical records was granted from each department. Using the medical records, we identified potential participants from the list of outpatients who visited the hospital; whomwere expected to return for follow-up visits and diabetes management. Inclusion criteria included: (1) age 18 years or over; (2) attending the outpatient department; (3) previous diagnosis with type 2 DM for 3 months or longer at the time of the study, and (4) able to communicate unassisted in the Nepali language. We excluded patients who were dependent on other family members for daily living, those with cognitive 
impairment or nervous system disability, those with serious comorbidity and those who lived alone. Data collectors approached potential participants, informed them about the study, and asked those who showed a willingness to participate for their written informed consent. After the participant read and signed the informed consent form, they were interviewed using a structured questionnaire.

Modified versions of the summary of diabetes selfcare activities (SDSCA) ${ }^{13}$ coupled with the diabetes family behavior checklist (DFBC) $)^{14}$ were used to measure selfcare practices and perceived family support, respectively. These instruments were first translated by an expert from English to Nepali, and then translated back to English by another expert; whom had not been exposed to the source documents. Discrepancies between the two English versions were used to identify potential translation issues in the Nepali version, which was then resolved by the investigators and the translators to obtain the final version.

\section{Measurement of diabetes self-care behaviors}

Self-care behaviors included five domains: (1) medication adherence; (2) physical activity; (3) dietary behaviors; (4) self-monitoring of blood glucose (SMBG) and (5) foot care. We kept the questions regarding medication adherence, physical activity, SMBG and foot care as they appeared on the SDSCA instrument, and we modified the questions regarding dietary behaviors to suit the local context. Firstly, Nepalese people tend to have 2 big meals per day, however, Nepalese health personnel generally recommend people with diabetes to have 5 small meals throughout the day. We decided to replace the question: "How many of the last 7 days have you followed a healthy eating plan?" with the question: "How many days (within the last 7 days) did you eat 5 or more small meals per day?”. Furthermore, Nepalese people tend to eat one cup/bowl of vegetables per meal, but fruit consumption varies, based on various factors. We; therefore, replaced the question: "On how many of the last 7 days did you eat five or more servings of fruits or vegetables?" with two separate questions. The first one being: "On how many of the last 7 days did you consume 1 cup/bowl of fruit per day?", and the second being: "On how many of the last 7 days did you consume 2 cups/bowls of vegetables per day?". In addition, an offering of sweets or mithai, which contain a high concentration of sugar, and are generally deep-fried in oil or ghee, is a common practice in Nepali culture during either festivals or on special occasions. Offers of sweets or mithai may come with undue pressure: it is considered polite to accept the offered sweets, while any refusal is considered rude. We thus added one additional question in the diet domain regarding the refusal of offered sweets/mithai within the past month.

\section{Measurement of perceived family support among people with type 2 diabetes}

We measured perceived family support using the DFBC." The DFBC consists of 21 items on a 5-point scale, reflecting the frequency of support provided by family members: (1) represents no support provided at all, (2) represents not more frequently than twice a month, (3) indicates more than twice a month, up to once a week, (4) represents more than once a week, up to several times a week, and (5) indicates at least once a day. The study instrument included five additional items, from the original DFBC, to suit the Nepali context of diabetes control, such as serving or requesting to have more vegetables than rice. White rice, which has a high glycemic index ${ }^{15}$, occupies the major portions of each meal in every household in Nepal. Healthcare practitioners generally recommend diabetic patients to have more vegetables than rice at each meal, so as to potentially lower the glycemic index of the meal. We also added items on serving, or requesting five 
or more small meals per day; and whether family members did: "Not let you buy sweets" and: "Not let you eat offered sweets", as well as whether family members "(Prepared) a separate meal for you during occasions". This was done to adapt the study instrument to a Nepali context.

We checked the completed questionnaires for completeness prior to data entry, which was conducted using EpiData version 3.1. Univariate descriptive analysis was performed to present the distribution of basic characteristics of study participants, self-care activities, and family support. Exploratory factor analysis was performed to identify the underlying components of perceived family support. All data analyses were conducted using the $\mathrm{R}$ language and environment.

Regarding diabetes self-care behaviors, medication adherence was defined as: whether the respondent took their prescribed medicine/insulin on all seven days of the past week. In rregards to physical activity, the original questionnaire measured physical activity using two items: frequency of physical activity related to work/household chores, and frequency of recreational physical activity. We combined these two items into one, and categorized participants into sedentary, moderately active and active. Sedentary patients included those who did not do any chores, nor performed any recreational physical activity during the past week. Moderately active patients referred to those who did some chores or performed recreational physical activity for fewer than 7 days in the past week, while active patients referred to participants who did chores or performed recreational physical activity for 7 days in the past week. In terms of dietary behaviors, we classified participants as having adherence to diet if; for the past 7 days, they had five or more small meals every day, consumed at least 2 bowls of vegetables every day and 1 or more bowls of fruit every day, consumed fatty food or red meat once or not at all, or within the past month, refused sweets when offered to them. We considered participants who monitored blood glucose levels three or more times during the last seven days as having adequate adherence to SMBG, following the "guideline for selfmonitoring of blood glucose in adults with diabetes". ${ }^{16}$ We defined foot care behavior adherence according to whether the participant checked his/her feet, and the inside of his/her shoes every day in the last seven days. ${ }^{17}$

We dichotomized responses to the family support items as: "Never engaged in the behavior" (response 1) vs. "Ever engaged in the behavior" (response 2-5), and presented the prevalence of family support behaviors using descriptive statistics. We also used this dichotomized scale in exploratory factor analysis (EFA). Of the 19 questions, on our modified DFBC, we excluded 2 items where the prevalence was over $90.0 \%$; for example, items whose answers were too homogeneous to distinguish patterns ("eat at the same time as you" and "let you sleep rather than waking you up for medicine"). We created a scree plot to estimate the number of factors to identify, and performed EFA using orthogonal rotation. We retained questions where the factor loading exceeded 4.0 for the subsequent round of EFA, so as to create the most parsimonious factors. We found that 7 question items; for example, (How often do family members) "suggest things that help you to take your medicines/insulin on time?", "help you to decide changes based on glucose results?", "encourage you to participate in sports?", "criticize you for not recording your blood glucose results?", "eat other food that is not part of your diabetic diet?", "not let you eat offered sweets?", and “prepare a separate meal for you during special occasions?" were removed as all these variables that did not load on any factor with a loading higher than 0.40 . To validate the identified family support factors, we derived the individual score for each factor, and assigned an arbitrary cut-off point at the $75^{\text {th }}$ percentile of each factor, so as to classify the level of family support in the factor as: "High" $\left(75^{\text {th }}\right.$ percentile or 
higher) or: "Low" (below $75^{\text {th }}$ percentile). These were then cross-tabulated with the prevalence of the dichotomized responses for each item of family support behavior.

This research was approved by the Institutional Review Board of Prince of Songkla University, Hat Yai, Thailand (REC. 62-204-19-9) and the Nepal Health Research Council (Reg. no. 588/2019).

\section{Results}

We approached 428 eligible patients in the outpatient departments of TUTH, of which 411 consented to participate (96.0\% response rate). More than half of the participants were female, and almost three-quarters were between the ages of 36 to 65 (Table 1). The most common ethnicity was Brahmin. Nearly all participants were married $(93.7 \%)$, more than half earned less than 10,000 Nepalese Rupee [\$90 United States dollar (\$)] per month and $60.0 \%$ lived in a nuclear family. Three-quarters had had diabetes for more than 12 months, and nearly half were on two or more medications for diabetes. Most participants had at least one comorbidity; the most common being hypertension. Nearly all (98.3\%) participants received a fasting blood sugar test, while testing for $\mathrm{HbA} 1 \mathrm{c}$ was relatively uncommon (31.1\%).

Among participants who were prescribed oral hypoglycemic agents and insulin, nearly all took medicines daily during the past 7 days (Table 2). Most participants had been physically active every day during the past 7 days. Adequate vegetable consumption was more common than adequate consumption of fruits, and having 5 or more small meals per day. More than half of the participants ate fatty food, or red meat only once, or had not during the last 7 days, and nearly three quarters had refused offered sweets within the past month. SMBG was not a common practice. Half of the participants had checked their feet every day within the last 7 days; whereas, less than a third had checked the inside of their shoes every day within the last seven days.
Table 1 Basic characteristics and health profiles of study participants $(n=411)$

\begin{tabular}{|c|c|}
\hline Characteristic & Frequency (\%) \\
\hline Gender: Female & $234(56.9)$ \\
\hline \multicolumn{2}{|l|}{ Age group (years) } \\
\hline $21-35$ & $47(11.4)$ \\
\hline $36-50$ & $119(29.0)$ \\
\hline $51-65$ & $177(43.1)$ \\
\hline $66-80$ & $64(15.6)$ \\
\hline $81-95$ & $4(1.0)$ \\
\hline \multicolumn{2}{|l|}{ Ethnicity } \\
\hline Brahmin & $125(30.4)$ \\
\hline Chhetri & $67(16.3)$ \\
\hline Newar & $60(14.6)$ \\
\hline Janajati & $107(26.0)$ \\
\hline Dalit & $17(4.1)$ \\
\hline Others & $35(8.5)$ \\
\hline \multicolumn{2}{|l|}{ Marital status } \\
\hline Never married & $7(1.7)$ \\
\hline Married & $385(93.7)$ \\
\hline Widowed & $19(4.6)$ \\
\hline \multicolumn{2}{|l|}{ Current address } \\
\hline Within Kathmandu & $224(54.5)$ \\
\hline Outside Kathmandu & $187(45.5)$ \\
\hline \multicolumn{2}{|l|}{ Education } \\
\hline Illiterate (no formal education) & $132(32.1)$ \\
\hline Literate (no formal education) & $69(16.8)$ \\
\hline Primary school level (grades $1-5$ ) & $28(6.8)$ \\
\hline $\begin{array}{l}\text { Lower secondary and secondary (grades } \\
6-10)\end{array}$ & $32(7.8)$ \\
\hline $\begin{array}{l}\text { School leaving certificate and higher } \\
\text { secondary }\end{array}$ & $100(24.3)$ \\
\hline University degree or higher & $50(12.2)$ \\
\hline \multicolumn{2}{|l|}{ Income range (monthly; Nepali rupees) } \\
\hline$<10,000$ & $216(52.6)$ \\
\hline $10,000-20,000$ & $96(23.4)$ \\
\hline$>20,000-30,000$ & $55(13.4)$ \\
\hline$>30,000-40,000$ & $27(6.6)$ \\
\hline$>40,000$ & $17(4.1)$ \\
\hline \multicolumn{2}{|l|}{ Family type } \\
\hline Nuclear family & $247(60.1)$ \\
\hline Joint/extended family & $164(39.9)$ \\
\hline \multicolumn{2}{|l|}{ Duration of diabetes } \\
\hline 3-12 months & $99(24.1)$ \\
\hline$>12$ months -5 years & $167(40.6)$ \\
\hline$>5-10$ years & $80(19.5)$ \\
\hline$>10$ years & $65(15.8)$ \\
\hline \multicolumn{2}{|l|}{ Diabetes treatment } \\
\hline Oral hypoglycemic agent only & $284(69.1)$ \\
\hline Oral hypoglycemic agent and insulin & $53(12.9)$ \\
\hline Insulin only & $17(4.1)$ \\
\hline
\end{tabular}


Table 1 (continued)

\begin{tabular}{ll}
\hline Characteristic & Frequency (\%) \\
\hline None & $55(13.4)$ \\
Others & $2(0.5)$ \\
Number of drugs & \\
None & $55(13.4)$ \\
One & $161(39.2)$ \\
Two or more & $187(45.5)$ \\
Don't know & $8(1.9)$ \\
Comorbidities & \\
Hypertension & $151(36.7)$ \\
Chronic obstructive pulmonary disease & $9(2.2)$ \\
Cardiovascular diseases other than & $58(14.1)$ \\
hypertension & \\
Kidney disease & $9(2.2)$ \\
Cerebrovascular disease & $10(2.4)$ \\
Thyroid disease & $34(8.3)$ \\
Others & $33(8.2)$ \\
Had one or more comorbidities & $219(53.3)$ \\
Fasting blood sugar (mg/dl) ${ }^{2}$ & \\
Controlled $(\leq 130)$ & $175(42.6)$ \\
Uncontrolled $(>130)$ & $229(55.7)$ \\
Not measured & $7(1.7)$ \\
Glycated hemoglobin level & \\
Controlled $(<7 \%)$ & $45(10.9)$ \\
Uncontrolled $(\geq 7 \%)$ & $83(20.2)$ \\
Not measured & $283(68.9)$ \\
\hline
\end{tabular}

'dyslipidemia, psychiatric illness, hyperuricemia

${ }^{2}$ milligrams per deciliter

Table 3 shows a frequency list of family behaviors, as reported by the participants. The three most commonly reported family support behaviors were eating at the same time as the participants (98.1\%), suggesting ways to help participants take medicine/insulin on time (89.5\%), and helping participants to decide on changes based on glucose results (84.2\%). The least commonly reported family support behaviors included letting the participants sleep, rather than rousing them to take their medicine (7.5\%), criticizing the participants for not recording blood glucose results $(29.2 \%)$ and criticizing the participants for not being physically active (33.3\%).
Table 2 Diabetes self-care practices of study participants ( $n=411$ unless stated otherwise)

\begin{tabular}{|c|c|}
\hline Self-care behaviors & Frequency $(\%)$ \\
\hline \multicolumn{2}{|l|}{ Medication adherence } \\
\hline Oral medicine ( $n=340$ patients) & $334(98.2)$ \\
\hline Insulin ( $\mathrm{n}=70$ patients) & $70(100.0)$ \\
\hline \multicolumn{2}{|l|}{ Physical activity } \\
\hline Sedentary* & $23(5.6)$ \\
\hline Moderately active ${ }^{\star *}$ & $33(8.0)$ \\
\hline Active $^{* \star *}$ & $355(86.4)$ \\
\hline \multicolumn{2}{|l|}{ Dietary behavior } \\
\hline Ate $\geq 5$ small meals ${ }^{\dagger}$ & $63(15.3)$ \\
\hline Ate $\geq 2$ bowls of vegetables $^{\dagger}$ & $322(78.3)$ \\
\hline Ate $\geq 1$ bowl of fruits ${ }^{\dagger}$ & $186(45.3)$ \\
\hline Ate fatty food or red meat ${ }^{\ddagger}$ & $228(55.5)$ \\
\hline $\begin{array}{l}\text { Refused offered sweets within the past } \\
1 \text { month }\end{array}$ & $287(70.0)$ \\
\hline \multicolumn{2}{|l|}{ Self-monitoring of blood glucose } \\
\hline Monitored blood glucose level ${ }^{p}$ & 59 (14.4) \\
\hline \multicolumn{2}{|l|}{ Foot care } \\
\hline Checked feet $^{\dagger}$ & $210(51.1)$ \\
\hline Checked inside of shoes $^{\dagger}$ & $135(32.8)$ \\
\hline
\end{tabular}

${ }^{\dagger}$ Every day in the last 7 days. ${ }^{\ddagger}$ At most once in the last 7 days.

${ }^{\mathbb{P}}$ At least three times in the last 7 days.

*Sedentary: did not perform chores or recreational physical activity in the past 7 days

**Moderately active: performed chores or recreational physical activity, for a total of $<7$ days in the past 7 days

${ }^{* * *}$ Active: performed chores or recreational physical activity every day in the past 7 days

Exploratory factor analyses yielded 3 factors of family support behaviors; as shown in Table 4. The behaviors that loaded onto the first factor included: nagging about testing blood sugar level, nagging about following the diet, arguing with the participant about self-care activities and preventing the participants from accepting offered sweets. As most of these activities were associated with control and criticism, we labeled this factor: "Authoritarian behavior". The behaviors that loaded onto the second factor included: praising the participants 
Table 3 Diabetes Family Behavior Checklist; as reported by study participants

\begin{tabular}{|c|c|}
\hline Family behavior & $\begin{array}{l}\text { "Ever" performed } \\
\text { Frequency }(\%)\end{array}$ \\
\hline Ate at the same time as you & $403(98.1)$ \\
\hline Suggested things that helped you to take medicines/insulin on time & $368(89.5)$ \\
\hline Helped you to decide changes, based on your glucose results & $346(84.2)$ \\
\hline Planned family activities that fit your diabetes self-care & $329(80.0)$ \\
\hline Prepared a separate meal for you during special occasions & $320(77.9)$ \\
\hline Bought things for you to carry in case of hypoglycemia & $317(77.1)$ \\
\hline Served you/requested you to have more vegetables than rice & $304(74.0)$ \\
\hline Served you/requested you to have 5 or more small meals & $303(73.7)$ \\
\hline Nagged you about following a diet & $300(73.0)$ \\
\hline Argued with you about diabetes self-care activities & $296(72.0)$ \\
\hline Nagged about testing blood sugar level & $295(71.8)$ \\
\hline Gave praise when you followed a diet & $281(68.4)$ \\
\hline Prevented you from eating sweets offered to you & $238(57.9)$ \\
\hline Congratulated you for adhering to your diabetes self-care & $228(55.5)$ \\
\hline Ate other food that is not part of your diabetic diet & $227(55.2)$ \\
\hline Encouraged you to participate in sports & $175(42.6)$ \\
\hline Prevented you from buying sweets & $162(39.4)$ \\
\hline Exercised with you & $153(37.2)$ \\
\hline Criticized you for not being physically active & $137(33.3)$ \\
\hline Criticized you for not recording your blood glucose results & $120(29.2)$ \\
\hline Let you sleep rather than waking you to take your medicine & $31(7.5)$ \\
\hline
\end{tabular}

Table 4 Results of factor analysis of perceived family support; according to diabetes patients $(n=411)$

\begin{tabular}{|c|c|c|c|}
\hline Factor loadings & $\begin{array}{l}\text { Factor } 1 \\
\text { (Authoritarian) }\end{array}$ & $\begin{array}{l}\text { Factor } 2 \\
\text { (Supportive) }\end{array}$ & $\begin{array}{l}\text { Factor } 3 \\
\text { (Planning) }\end{array}$ \\
\hline Praised you when you followed the diet & -0.121 & $0.565^{\star}$ & \\
\hline Nagged you about testing blood sugar level & $0.582^{*}$ & & \\
\hline Criticized you for being physically inactive & 0.359 & $0.512^{*}$ & \\
\hline Nagged you about following the diet & $0.889^{*}$ & -0.101 & \\
\hline Argued with you about diabetes self-care activities & $0.738^{*}$ & & 0.340 \\
\hline Planned family activities that fit your diabetes self-care routine & 0.314 & -0.112 & $0.762^{*}$ \\
\hline Congratulated you for adhering to your diabetes self-care routine & & $0.607^{*}$ & \\
\hline Exercised with you & & $0.426^{*}$ & \\
\hline Bought things for you to carry in case of hypoglycemia & & & $0.514^{\star}$ \\
\hline Served you/requested you to have more vegetables than rice & & $0.469^{*}$ & \\
\hline Prevented you from accepting offered sweets & $0.404^{*}$ & & 0.244 \\
\hline Served you/requested you to have 5 or more small meals & & $0.567^{*}$ & \\
\hline Percent variance explained & $17.5 \%$ & $14.3 \%$ & $8.0 \%$ \\
\hline Eigen values & 2.1 & 1.7 & 1.0 \\
\hline
\end{tabular}

${ }^{*}$ Factor loading $>0.40$ 
when following the diet, criticizing the participants for being physically inactive, congratulating the participants for adhering to self-care, exercising with the participants, serving or requesting the participants to eat more vegetables and to have smaller meals. As most of these behaviors were associated with showing support, we labeled this factor: "Supportive behavior". The behaviors that loaded onto the third factor included: planning family activities and buying things for the participants to carry in case of hypoglycemia. These behaviors were labelled as: "Planning behaviors". We validated the results of exploratory factor analyses using an arbitrary categorization of the behavioral levels, based on the factor analysis score of each factor, into high (above the $75^{\text {th }}$ percentile) and low $\left(75^{\text {th }}\right.$ percentile or lower) levels of "Authoritarian", "Supportive”, and "Planning" behaviors. The prevalence of family support behaviors among those in the "high" group are shown in Table 5.

\section{Discussion}

This study investigated sociodemographic and disease characteristics, self-care practices, and perceived family support among people with type 2 diabetes receiving care at a tertiary center hospital in Kathmandu, Nepal. We used validated instruments, tailored to suit the context of the study setting, and found a high level of adherence to self-care behaviors in the domains of medication adherence and physical activity. However, adherence to dietary behaviors, self-monitoring of blood glucose, and foot care varied. Family support behaviors appeared to exist in three domains, but the prevalence of family support behaviors within each domain was very heterogeneous.

The most performed self-care practice in this study was medication adherence (>98.0\%), followed by physical activities (>94.0\%). This high percentage of medication compliance was also found in studies from Ethiopia, China and Malaysia. ${ }^{18-20}$ The high level of compliance could be due to the influence of the study setting; wherein, there was a high level of trust in, and respect for, the attending clinicians. ${ }^{21}$ Adherence to physical activity in our study was higher than in Malaysia, India and Ethiopia. ${ }^{18,20,22}$ A possible reason is that we considered workhousehold related chores to be physical activity, unlike in other studies. Howbeit, this difference might also

Table 5 Prevalence of reported family support among those with a high level ( $75^{\text {th }}$ percentile ranking or higher) of authoritarian, supportive and planning domains of family support

\begin{tabular}{|c|c|c|c|}
\hline Variables & $\begin{array}{l}\text { Factor } 1(\%) \\
\text { (Authoritarian) }\end{array}$ & $\begin{array}{l}\text { Factor } 2(\%) \\
\text { (Supportive) }\end{array}$ & $\begin{array}{l}\text { Factor } 3(\%) \\
\text { (Planning) }\end{array}$ \\
\hline Praised you when you followed a diet & 73.0 & 98.0 & 77.6 \\
\hline Nagged about testing blood sugar level & 100.0 & 87.1 & 50.0 \\
\hline Criticized you for not being physically active & 88.0 & 88.1 & 10.2 \\
\hline Nagged you about following a diet & 100.0 & 76.2 & 48.0 \\
\hline Argued with you about diabetes self-care activities & 100.0 & 73.3 & 63.3 \\
\hline Planned family activities that fit your diabetes self-care & 88.0 & 77.2 & 100.0 \\
\hline Congratulated you for sticking in your diabetes self-care & 69.0 & 97.0 & 76.5 \\
\hline Exercised with you & 49.0 & 71.3 & 33.7 \\
\hline Bought things for you to carry in case of hypoglycemia & 71.0 & 84.2 & 100.0 \\
\hline Served you/requested you to have more vegetables than rice & 91.0 & 99.0 & 74.5 \\
\hline Prevented you eat offered sweets & 86.0 & 62.4 & 56.1 \\
\hline Served you/requested you to have 5 or more small meals & 81.0 & 100.0 & 95.9 \\
\hline
\end{tabular}


be due to differences in lifestyles. Age could also have contributed to this difference, as more than four-fifths of our participants were less than 65 years of age, therefore they may have been able to perform daily physical activities.

Most of the participants had consumed two or more bowls of vegetables every day for the past week, whereas less than half had consumed one or more bowls of fruit. In Nepali cuisine, vegetables are a fundamental component of each meal, and families generally will make sure that each person has a cup of vegetables with each meal; regardless of their income. Fruit, on the other hand, is not considered as essential as vegetables, and will be consumed only by those who can afford it. Over half of all participants earned 10,000 Nepalese rupee (\$90 per month) or less, and this low level of income might explain the discrepancies between vegetable and fruit consumptions. Low consumption of fruit was also reported in studies from India. ${ }^{22,23}$ The prevalence of fatty foods or red meat consumption in this study was higher than in previous studies ${ }^{22,23}$, which may be due to the timing of our study. This study was conducted in between two major festivals of Nepal (Dashain and Tihar); wherein, the primary dishes cooked at these festivals consist of goat's meat along with deep-fried food.

One-tenth of respondents adhered to SMBG, a result similar to findings reported in Ethiopia and Ghana. $^{24,25}$ The perceived, higher cost of self-monitoring may have been the cause of low adherence to SMBG. ${ }^{26}$ The prevalence of checking one's own feet in this study was higher than in a study from Pakistan, but the prevalence of checking the inside of one's shoes was lower than the prevalence found in studies from Ethiopia and India. ${ }^{27-29}$ Further, quantitative analyses and qualitative data are needed for a better understanding of the low level of foot care adherence found in our study.

In contrast to the two domains of family support behaviors presented in the original DFBC instrument, our
EFA identified 3 domains; for example, "Authoritarian", "Supportive", and "Planning". The "Authoritarian" behaviors were similar to the non-supportive behaviors' subscale in the DFBC, while the "Supportive" behaviors were like the DFBC's supportive behaviors subscale. The additional family support behaviors of "Serve/request to have more vegetables than rice" and "Serve/request to have five or more small meals" loaded on the Supportive behaviors domain, while "Not letting you eat offered sweets" loaded on the Authoritarian behaviors domain, showing consistency between the questions tailored to the Nepali context and the domains in the original DFBC. The similarities of these findings warrant further investigation.

There are several advantages in adapting data collection tools to suit the local context in the study of diabetes-related behaviors, and potential behavioral determinants. In regards to the healthcare system: the lack of economic resources in Nepal has implications on both access to medical care and the patient's lifestyle. Medical and lifestyle recommendations for patients in highincome countries may not be applicable, nor appropriate for patients in low-resource settings. ${ }^{30}$ The value of food is also different in Nepal compared to high-income countries. Food is beyond nutrition; it is a means to develop, maintain and foster interpersonal relationships as well as bonds within and between both families and groups. ${ }^{31}$ Hence, changes in dietary restrictions, or intake patterns can be misperceived as rejection or refusal of interpersonal relationships. Nepalese families function on a collective basis and give deference to their elders, and so these family values imply that family members may be reluctant to engage in conflicting behaviors, or to criticize diabetic patients who are often the more senior members of the family. Measuring food intakeand family support in ways that are consistent with these unique values helps to create a better understanding of the distribution of behaviors, along with potential behavioral determinants 
in a given population in manners that are relevant to actual health education and public health practices. To the best of our knowledge, this is the first study to measure diabetes self-care behaviors, and family support with standardized tools adapted to the Nepali context. However, several limitations should be taken into consideration. Firstly, we did not undergo multiple iterations for validation of the question items that were tailored to the Nepali context, which might have potentially undermined the validity of the findings. In addition, all responses in this study were self-reported. If patients believed that interviewers expected the participants to have a high level of adherence to self-care behaviors, social desirability could have influenced the responses, and the participants could have over-reported the prevalence of self-care behaviors. Lastly, this study was a hospital-based cross-sectional study, conducted in only one tertiary hospital in the capital city of Kathmandu. The findings of this study cannot be generalized to the context of rural Nepal, where most of the population lives and healthcare resources are more limited.

\section{Conclusion}

We found variations in self-care activities and family support among people with type 2 diabetes attending outpatient services at a teaching hospital in Kathmandu, Nepal. Our study presented data from questions tailored to the local context, which may be helpful for future health promotion programs in the region as well as providing a methodological basis for future studies in other low and middle-income countries.

\section{Acknowledgement}

We are grateful to all study participants, Tribhuvan University Teaching Hospital, and to Miss Lalla Maharjan and Miss Sanchita Karki for their help during the data collection process.

\section{Funding sources}

The study was supported by a grant from the Thailand International Cooperation Agency.

\section{Conflict of interest}

None

\section{References}

1. International Diabetes Federation. IDF diabetes atlas [homepage on the Internet]. Brussels: IDF; 2017 [cited 2019 May 16]. Available from: https://diabetesatlas.org/

2. United Kingdom Prospective Diabetes Study (UKPDS) Group. Intensive blood-glucose control with sulphonylureas or insulin compared with conventional treatment and risk of complications in patients with type 2 diabetes (UKPDS 33). Lancet 1998;352:837-53.

3. Ahmed Z, Yeasmeen F. Active family participation in diabetes self-care: a commentary. Diabetes Manag 2016;6:104-7.

4. World Health Organization. Adherence to long-term therapies: evidence for action. Geneva: WHO; 2003;p.198.

5. Rhee MK, Slocum W, Ziemer DC, Culler SD, Cook CB, El-Kebbi IM, et al. Patient adherence improves glycemic control. Diabetes Educ 2005;31:240-50.

6. D’Souza MS, Karkada SN, Parahoo K, Venkatesaperumal R, Achora S, Cayaban ARR. Self-efficacy and self-care behaviours among adults with type 2 diabetes. Appl Nurs Res 2017;36:25-32.

7. Fisher LW, Chesla CA, Bartz RJ, Gilliss C, Skaff MA, Sabogal $F$, et al. The family and type 2 diabetes: a framework for intervention. Diabetes Educ 1998;24:599-607.

8. Mayberry LS, Osborn CY. Family support, medication adherence, and glycemic control among adults with type 2 diabetes. Diabetes Care 2012;35:1239-45.

9. Tang TS, Brown MB, Funnell MM, Anderson RM. Social support, quality of life, and self-care behaviors among African Americans with type 2 diabetes. Diabetes Educ 2008;34: 266-76.

10. Scarton L, Velazquez I, O’Neal LJ, lyerm S, Cannady T, Choate $A$, et al. Developing a culturally tailored multigenerational intervention to prevent and manage type 2 diabetes in American Indian families living in rural settings: 
Findings from a focus group study. Res Nurs Health 2019; 42:226-33.

11. Chesla CA, Chun KM, Kwan CML. Cultural and family challenges to managing type 2 diabetes in immigrant Chinese Americans. Diabetes Care 2009;32:1812-6.

12. Sohal $T$, Sohal $P$, King-Shier KM, Khan NA. Barriers and facilitators for type-2 diabetes management in South Asians: a systematic review. PLoS One 2015;10. doi: 10.1371/ journal.pone.0136202.

13. Toobert DJ, Hampson SE, Glasgow RE. The summary of diabetes self-care activities measure: results from 7 studies and a revised scale. Diabetes Care 2000;23:943-50.

14. Lewin AB, Geffken GR, Heidgerken AD, Duke DC, Novoa W, Williams LB, et al. The diabetes family behavior checklist: a psychometric evaluation. J Clin Psychol Med Set 2005;12: 315-22.

15. Sun Q, Spiegelman D, van Dam RM, Holmes MD, Malik VS, Willett WC, et al. White rice, brown rice, and risk of type 2 diabetes in US men and women. Arch Intern Med 2010;170: 961-9.

16. Wandsworth Clinical Commissioning Group. Self monitoring blood glucose guidelines [monograph on Internet]. London: Wandsworth Clinical Commissioning Group [cited 2020 Apr 26]. Available from: https://www.wandsworthccg.nhs.uk/ newsAndPublications/Publications/Diabetes/Self\%20 Monitoring\%20Blood\%20Glucose\%20Guidelines.pdf

17. The Global Diabetes Community. Foot checks for diabetes [homepage on Internet]. Coventry: Diabetes Digital Media Ltd; 2019 [cited 2020 May 7]. Available from: https://www. diabetes.co.uk/foot-care/foot-checks.html

18. Bonger Z, Shiferaw S, Tariku EZ. Adherence to diabetic selfcare practices and its associated factors among patients with type 2 diabetes in Addis Ababa, Ethiopia. Patient Pref Adher 2018;12:963-70.

19. Yin X, Savage C, Toobert D, Wei Pan, Whitmer K. Adaptation and testing of instruments to measure diabetes selfmanagement in people with type 2 diabetes in Mainland China. J Transcult Nurs 2008;19:234-42.

20. Gunggu A, Thon CC, Whye Lian C. Predictors of diabetes self-management among type 2 diabetes Patients. J Diabetes Res 2016;2016:9158943.

21. Bhandari P, Kim M. Self-care behaviors of nepalese adults with type 2 diabetes: a mixed methods analysis. Nurs Res 2016;65:202-14

22. Rajasekharan D, Kulkarni V, Unnikrishnan B, Kumar N, Holla R, Thapar R. Self-care activities among patients with diabetes attending a tertiary care hospital in Mangalore Karnataka, India. Ann Med Health Sci Res 2015;5:59-64.

23. Gopichandran V, Lyndon S, Angel MK, Manayalil BP, Blessy KR, Alex RG, et al. Diabetes self-care activities: a communitybased survey in urban southern India. Natl Med J India 2012; 25:14-7.

24. Berhe KK, Gebru HB, Kahsay HB, Kahsay AA, Kalayou. Assessment of self care management and its associated factors among type 2 diabetes patients in Mekelle Hospital and Ayder Referral Hospitals, Mekelle City, Tigray, Northern Ethiopia, 2012/13. Global J Med Res 2017;17:31-48.

25. Mogre V, Abanga ZO, Tzelepis F, Johnson NA, Paul C. Adherence to and factors associated with self-care behaviours in type 2 diabetes patients in Ghana. BMC Endocr Disord $2017 ; 17: 20$

26. Skeie S, Thue G, Nerhus K, Sandberg S. Instruments for self-monitoring of blood glucose: comparisons of testing quality achieved by patients and a technician. Clin Chem 2002;48:994-1003.

27. Saeed N, Zafar J, Atta A. Frequency of patients with diabetes taking proper foot care according to international guidelines and its impact on their foot health. J Pak Med Assoc 2010;60: $732-5$.

28. Moreno Hernandez MI, Trilla Soler M, Espluga Capdevila A, Mengual Miralles N, Bundo Vidiella $M$, et al. Self care and risk factors of diabetic foot in patients with type II diabetes mellitus. Aten Primaria 1997;20:185-90.

29. Uma MR, Sowiya KR, Kavin S. Self-care practices among type II diabetics attending primary health centre, Thiruvallur district, Tamil Nadu. Int $\mathrm{J}$ Community Med Public Health 2017;4:2745-9.

30. Dagenais GR, Leong DP, Rangarajan S, Lanas F, Lopez-Jaramillo P, Gupta R, et al. Variations in common diseases, hospital admissions, and deaths in middle-aged adults in 21 countries from five continents (PURE): a prospective cohort study. Lancet 2020;395:785-94.

31. Prakash J, Waisundara V, Prakash V. Nutritional and health aspects of food in South Asian Countries. Cambridge: Academic Press; 2020;p.365 